\title{
Loss of Synaptic Depression in Mammalian Anterior Cingulate Cortex after Amputation
}

\author{
Feng Wei, Ping Li, and Min Zhuo \\ Departments of Anesthesiology, and Anatomy and Neurobiology, Washington University Medical Center, Washington \\ University School of Medicine, St. Louis, Missouri 63110
}

Two forms of activity-dependent long-term depression (LTD) in the CNS, as defined by their sensitivity to the blockade of NMDA receptors, are thought to be important in learning, memory, and development. Here, we report that NMDA receptorindependent LTD is the major form of long-term plasticity in the anterior cingulate cortex (ACC). Both L-type voltage-gated calcium channels and metabotropic glutamate receptors are required for inducing LTD. Amputation of a third hindpaw digit in an adult rat induced rapid expression of immediate early genes in the ACC bilaterally and caused a loss of LTD that persisted for at least 2 weeks. Our results suggest that synaptic LTD in the ACC may contribute to enhanced neuronal responses to subsequent somatosensory stimuli after amputation.

Key words: synaptic plasticity; long-term depression; immediate-early gene; cingulate cortex; amputation; glutamate
The adult human somatosensory cortex is often represented with a distorted human figure on its surface to illustrate the somatotopic map. For a long period of time, it had been thought that this figure remained relatively stable in adults. Studies over the past 20 years have dramatically changed this view (Wall, 1988; Kaas, 1991; Gilbert and Wiesel, 1992; Merzenich and Sameshima, 1993; Ramachandran, 1993; Weinberger, 1995; Gilbert, 1996; Buonomano and Merzenich, 1998; Kilgard and Merzenich, 1998). Cortical representations in the mammalian brain are rather dynamic and can be modified by experience. Not only do plastic changes occur in adults, but they can happen on a rapid time scale (from a few minutes to several hours). It has been proposed that usedependent changes in synaptic strength, such as long-term potentiation (LTP) and long-term depression (LTD), may serve as key synaptic mechanisms of cortical plasticity (Tsumoto, 1992; Bliss and Collingridge, 1993; Bear and Malenka, 1994; Linden, 1994; Lisman, 1994; Larkman and Jack, 1995; Nicoll and Malenka, 1995; Singer, 1995; Bear and Abraham, 1996).

Although cortical reorganization acts as an adaptive mechanism during development and learning, it could also play a detrimental role in traumatic events, such as the loss of a limb. It has been demonstrated that cortical reorganization occurs after limb or digit amputation (Wall, 1977; Merzenich et al., 1984; Pons et al., 1991; Ramachandran et al., 1992, 1995; Florence et al., 1998; Jones and Pons, 1998; Kaas, 1998; Merzenich, 1998). Most human amputees experience phantom limb sensation or phantom pain (Sherman et al., 1980; Melzack, 1990; Jensen and Rasmussen, 1994), and the amount of cortical reorganization correlates with the extent of phantom pain (Flor et al., 1995; Birbaumer et al., 1997; Lorenz et al., 1998). A critical question is whether synaptic

Received June 22, 1999; revised Aug. 16, 1999; accepted Aug. 18, 1999.

This work was supported by grants from the McDonnell High Brain Function at Washington University and the National Institute on Drug Abuse. We want to thank Drs. Joseph Henry Steinbach and James E. Huettner for their helpful suggestions. Correspondence should be addressed to Min Zhuo, Department of Anesthesiology, Washington University, 660 South Euclid Avenue, St. Louis, MO 63110. E-mail: zhuom@morpheus.wustl.edu.

Copyright (C) 1999 Society for Neuroscience 0270-6474/99/199346-09\$05.00/0 mechanisms, which are implicated in the learning process, may contribute to plastic changes in the CNS after amputation.

The anterior cingulate cortex (ACC) forms a large region around the rostrum of the corpus callosum and is involved in emotional and attentive responses to internal and external stimulation (Devinsky et al., 1995; Rainville et al., 1997; Tolle et al., 1999). Recently, neuroimaging and electrophysiological studies in humans have shown that pain activates several limbic sites, including the ACC (Talbot et al., 1991; Vogt et al., 1996; Davis et al., 1997; Derbyshire et al., 1998; Lenz et al., 1998; Paulson et al., 1998; Hutchison et al., 1999). Further experiments demonstrate that the ACC receives nociceptive inputs in animals (Kenshalo et al., 1988; Sikes and Vogt, 1992; Traub et al., 1996; Vogt et al., 1996; Koyama et al., 1998). A previous report showed that only short-term potentiation but not LTP was recorded in vitro in slices from the ACC (Sah and Nicoll, 1991). LTD has not been investigated. In the present study, we first examined whether LTD serves as a form of synaptic plasticity in slices of adult ACC. We then examined the possible effect of hindpaw digit amputation on the synaptic plasticity in the ACC.

\section{MATERIALS AND METHODS}

In vitro electrophysiology. The ACC slices $(200 \mu \mathrm{m})$ from 7- to 21-d-old Sprague Dawley rats (Harlan Sprague Dawley, Indianapolis, IN) were used for whole-cell patch-clamp recordings. Under visual guidance recordings in individual layer II/III, cortical pyramidal cells were made using 3-5 M $\Omega$ electrodes without fire polishing. Recording electrodes contained (in mM): $110 \mathrm{Cs}-\mathrm{MeSO}_{3}, 5 \mathrm{MgCl}_{2}, 1$ EGTA, 40 HEPES sodium, $2 \mathrm{MgATP}$, and $0.1 \mathrm{Na}_{3} \mathrm{GTP}, \mathrm{pH}$ 7.2. The osmolarity was adjusted to 295-300 mOsm. Membrane potential was clamped at $-70 \mathrm{mV}$ (liquid junction potential not corrected). Series resistance was 15-40 M $\Omega$ and monitored throughout the experiments. Synaptic EPSCs were evoked by a bipolar stimulating electrode placed at layer V. Picrotoxin $(100 \mu \mathrm{M})$ was added to the perfusion solution. Currents were filtered at $1 \mathrm{kHz}$ and digitized at $5 \mathrm{kHz}$.

For field potential recordings, adult male Sprague Dawley rats (8-10 weeks) were anesthetized with $2 \%$ halothane and decapitated. Coronal ACC slices, $400-\mu \mathrm{m}$-thick, were rapidly prepared and maintained in an interface chamber at $28^{\circ} \mathrm{C}$ in which they were perfused with oxygenated $\left(95 \% \mathrm{O}_{2}\right.$ and $5 \% \mathrm{CO}_{2}$ ) artificial CSF (ACSF) consisting of (in mM): 124 
A

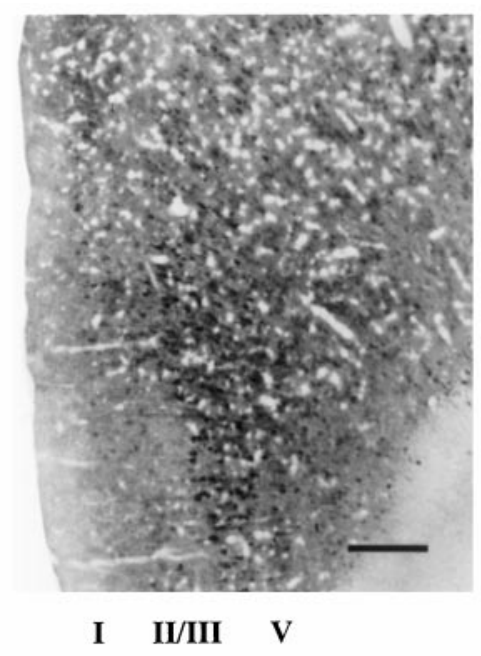

B

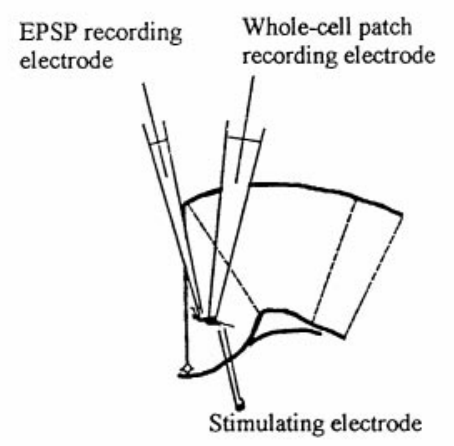

D

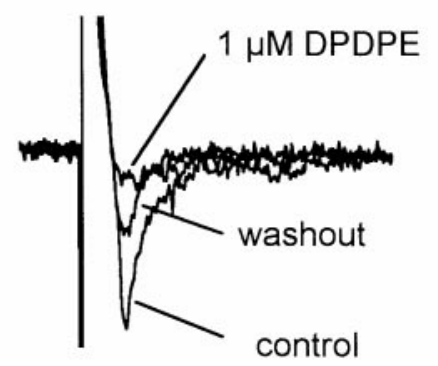

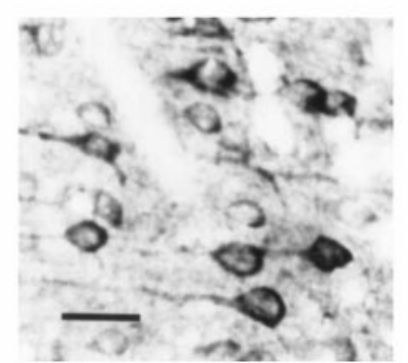

C

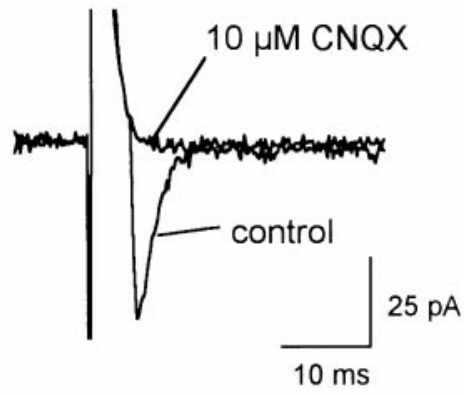

$25 \mathrm{pA}$

$10 \mathrm{~ms}$

$\mathrm{NaCl}, 4.4 \mathrm{KCl}, 25 \mathrm{NaHCO}_{3}, 1.0 \mathrm{NaH}_{2} \mathrm{PO}_{3}, 2.0 \mathrm{CaCl}_{2}, 2.0 \mathrm{MgSO}_{4}$, and 10 $\mathrm{D}$-glucose. A bipolar tungsten stimulating electrode was placed in layer $\mathrm{V}$, and extracellular field potentials were recorded with a glass microelectrode (filled with ACSF) inserted into layer II/III. Responses were evoked at $0.02 \mathrm{~Hz}$. In some experiments, two-pathway experiments were performed. A surgical cut was made between two stimulating electrodes. Responses to paired-pulse stimulation (with a $50 \mathrm{msec}$ interval) were used to confirm the independence of the two pathways. Low-frequency stimulation was only delivered to one pathway. In other experiments, we also recorded synaptic responses from the parietal cortex (PC) (see Fig. 7). Drugs were freshly prepared: voltage-gated L-type calcium channel blocker nimodipine $(10 \mu \mathrm{M})$, NMDA receptor antagonist AP-5 $(100 \mu \mathrm{M})$, and metabotropic glutamate receptor (mGluR) antagonist $(+)-\alpha$-methyl4-carboxylphenylglycine (MCPG) $(500 \mu \mathrm{M})$. Slices were pretreated with a drug for at least $30 \mathrm{~min}$ before low-frequency stimulation.

Immunocytochemistry. Under brief anesthesia with halothane, the third digit of the unilateral hindpaw of adult male rats was amputated. At $15 \min (n=3$ rats $), 45 \min (n=6), 90 \min (n=4), 120 \min (n=4), 2 \mathrm{~d}$ $(n=4)$, and 2 weeks $(n=4)$ after the amputation, rats were deeply anesthetized with halothane and perfused transcardially with $100 \mathrm{ml}$ of saline, followed by $500 \mathrm{ml}$ of cold $0.1 \mathrm{M}$ phosphate buffer (PB) containing
Figure 1. Excitatory synaptic transmission in the ACC. $A$, Laminar distribution of GluR2/3-immunoreactive neurons in the ACC (left) and high magnification of the labeled pyramidal neurons and their proximal dendrites in layer II/III from the left photograph (right). Scale bars: left, $250 \mu \mathrm{m} ;$ right, 50 $\mu \mathrm{m} . B$, Diagram of a cingulate cortical slice showing the placement of wholecell patch recording, field EPSP recording, and stimulating electrodes. $C, D$, Whole-cell patch recording of EPSCs recorded at $-70 \mathrm{mV}$ holding potential in normal medium (control) or $10 \mathrm{~min}$ after addition of $10 \mu \mathrm{M} C \mathrm{NQX}(C)$ or 1 $\mu \mathrm{M}$ DPDPE $(D)$. In a total of five experiments, CNQX blocked EPSCs, and DPDPE inhibited EPSCs to $57.3 \pm$ $11.3 \%$ of control.
4\% paraformaldehyde. Sham operations without amputation were performed as controls $(n=10)$. The brains were removed, post-fixed for 4 $\mathrm{hr}$, and then cryoprotected by storing in $30 \%$ sucrose in $0.1 \mathrm{M} \mathrm{PB}$ for $2 \mathrm{~d}$ at $4^{\circ} \mathrm{C}$. Coronal sections $(25-\mu \mathrm{m}$-thick) through the ACC were cut using a cryostat. Sections from sham and experimental animals were processed simultaneously for immunostaining of three immediate-early gene (IEG)-encoded proteins. Primary rabbit antibodies used included: antic-Fos (1:20,000; Oncogene Science, Uniondale, NY), antiphosphorylated cAMP response element-binding protein (pCREB) (1: 1000; Upstate Biotechnology, Lake Placid, NY), and anti-NGFI-A (1: 5000; a gift from Dr. Jeffrey D. Milbrandt at Washington University, St. Louis, MO). Secondary reactions with biotinylated goat anti-rabbit immunoglobulin (1:400; Vector Laboratories, Burlingame, CA) for $1 \mathrm{hr}$ were followed by avidin-biotin-peroxidase complexes (1:100; Vector Laboratories) for $1 \mathrm{hr}$. Diaminobenzadine with nickel was used as the final chromogen. In addition, for identification of AMPA receptor distribution in the cortical area, some ACC sections from normal rats $(n=$ $3)$ were performed with anti-GluR2/3 antibody(1:200; Chemicon, Temecula, CA) and then processed as above. Alternate sections, incubated in the absence of a primary antibody as an immunocytochemical control, showed no immunostaining. Sections from the bilateral ACC from 1.0 
Figure 2. Low-frequency stimulation produced LTD in the ACC. $A$, An example that low-frequency stimulation $(0.02 \mathrm{~Hz})$ produced a long-lasting depression of synaptic responses. Inset, Representative records of the EPSP recorded before and $30 \mathrm{~min}$ after $1 \mathrm{~Hz}$ stimulation. $B$, Summary results for LTD $(n=10 ; 36.3 \pm 6.3 \%$ of control $30 \mathrm{~min}$ after the stimulation; $p<0.01 \mathrm{com}$ pared with EPSPs before stimulation). $C, D$, Repetitive stimulation at $5 \mathrm{~Hz}$ for $3 \mathrm{~min}$ also produced synaptic depression (squares; $n=5 ; 50.4 \pm 6.0 \%$ of control; $p<$ 0.01 ), but $10 \mathrm{~Hz}$ stimulation for $1.5 \mathrm{~min}$ did not produce any depression (squares; $n=5 ; 80.8 \pm 11.9 \%$ of control).
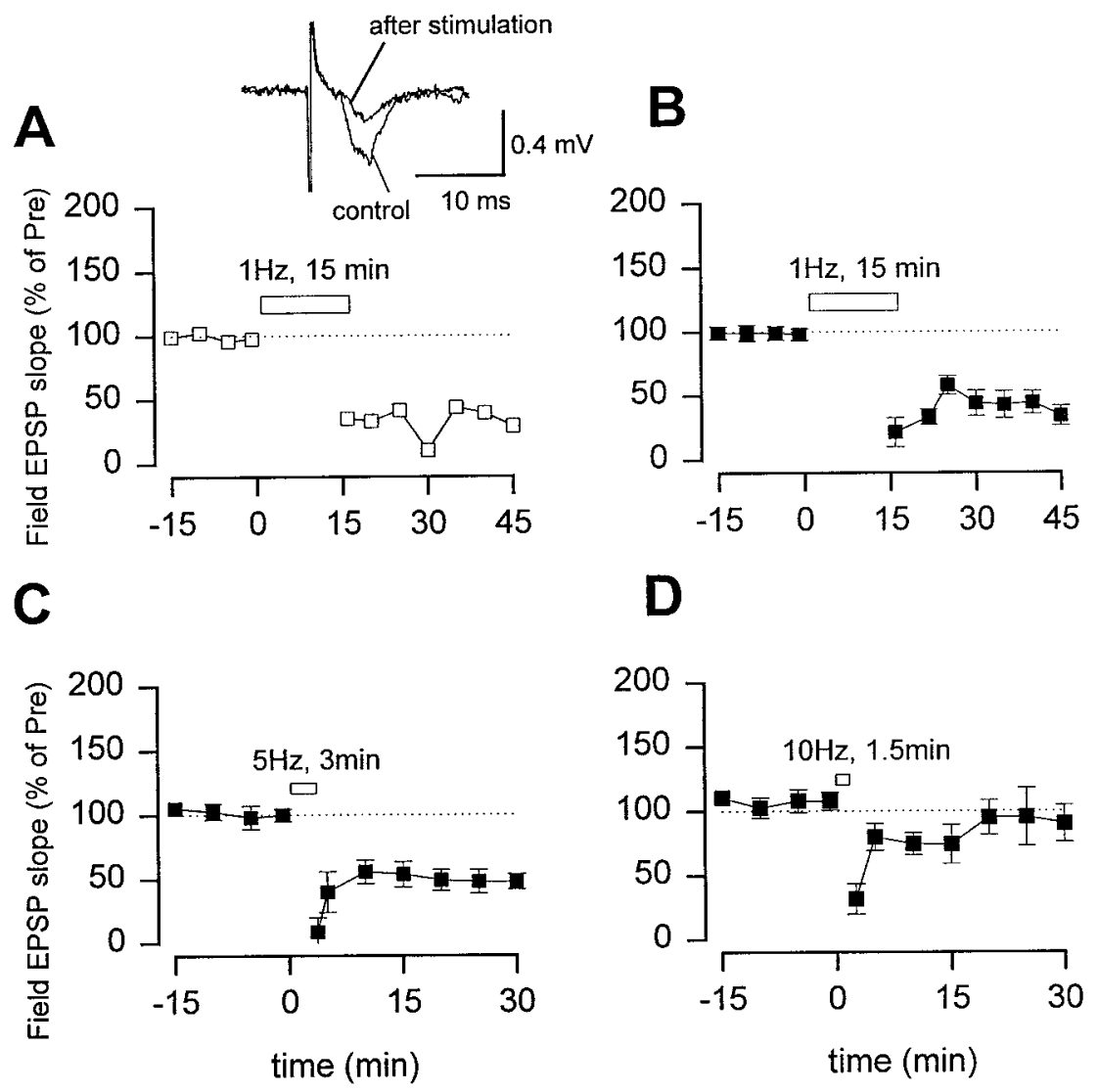

$\mathrm{mm}$ rostral to $0.8 \mathrm{~mm}$ caudal to bregma (Paxinos and Watson, 1997) were used for quantity. The number of IEG-expressed cells within an area of $750 \times 600 \mu \mathrm{m}$, including layers II-VI of the ACC, was plotted and counted. Two-way ANOVA was used to compare the number of labeled cells in different groups of animals. Post hoc Scheffe $F$ test was used to identify significant differences. $p<0.05$ was considered statistically significant.

\section{RESULTS}

\section{Glutamate-mediated postsynaptic transmission in the ACC}

Previous studies indicated that glutamate is the major fast excitatory neurotransmitter in the ACC (Sah and Nicoll, 1991; Tanaka and North, 1994). Thus, we first examined distribution of immunoreactivity for glutamate receptor subunit $2 / 3$, a representative of AMPA receptors. Many neurons in layers II-V of the ACC area were labeled. Most ACC pyramidal neurons in layers II/III and V display intense GluR2/3 immunostaining in the perikarayal cytoplasm and proximal dendrites (Fig. $1 A$ ). Wholecell patch-clamp recordings from ACC pyramidal cells showed that fast EPSCs were elicited by delivering focal electrical stimulation to layer V (Fig. $1 B$ ). When cells were held at $-70 \mathrm{mV}$, EPSCs were completely blocked by the AMPA/kainate receptor antagonist CNQX (10 $\mu \mathrm{M})$ (Fig. 1C). Consistent with a previous report (Tanaka and North, 1994), EPSCs were subject to opioid modulation. [D-Pen ${ }^{2,5}$ ]-enkephalin (DPDPE) $(1 \mu \mathrm{M})$, a selective $\delta$ receptor agonist, significantly inhibited EPSCs $(n=5 ; 57.3 \pm$ $11.3 \%$ of control; $p<0.05$ ) (Fig. 1D).

\section{LTD induced by low-frequency stimulation}

Excitatory synaptic transmission in slices from the ACC undergoes LTD. Field EPSPs recordings from ACC slices of adult rats showed that fast EPSPs induced by a bipolar electrode placed in layer $\mathrm{V}$ were mediated by AMPA/kainate receptors, because 10 $\mu \mathrm{M}$ CNQX blocked the response $(n=5)$. A stimulation protocol for inducing LTD in both the hippocampus and visual cortex (1 $\mathrm{Hz}$ for $15 \mathrm{~min}$ ) (Dudek and Bear, 1992; Mulkey and Malenka, 1992; Kirkwood et al., 1993) was used. Low-frequency stimulation produced long-lasting depression of synaptic responses (Fig. $2 A, B)$. Depression was frequency related. Repetitive stimulation at $5 \mathrm{~Hz}$ but not $10 \mathrm{~Hz}$ with the same number of pulses $(n=900)$ produced depression of synaptic responses (Fig. 2C,D).

To test whether LTD in the ACC is input specific, we performed two-pathway experiments in some slices (Fig. 3). Conditioning stimulation ( $1 \mathrm{~Hz}$ for $15 \mathrm{~min}$ ) was only delivered to one pathway. As showed in Figure $3 B-D$, whereas synaptic responses were significantly depressed in the stimulated pathway $(n=6$; $52.0 \pm 7.3 \%$; $p<0.01$ compared with EPSPs before the stimulation), synaptic responses in the second, independent pathway were not significantly affected $(101.1 \pm 6.2 \%$ of control). This result indicates that LTD in the ACC is input-specific.

Several types of postsynaptic receptors or channels have been reported to contribute to the induction of LTD, including voltagegated calcium channels, NMDA receptors, and mGluRs (Bashir et al., 1993; Kato 1993; Boshakov and Siegelbaum, 1994; Cummings et al., 1996; Deisseroth et al., 1996; Oliet et al., 1997). To test their roles in cingulate LTD, we performed experiments in the presence of selective antagonists. Nimodipine $(10 \mu \mathrm{M})$ completely blocked the induction of LTD (Fig. $4 A$ ), although basal synaptic responses were not significantly affected. In contrast, 100 $\mu \mathrm{M}$ AP-5 did not affect LTD (Fig. 4B). MCPG (500 $\mu \mathrm{M})$, a metabotropic glutamatergic receptor antagonist, also blocked LTD (Fig. 4C). These results suggest that both L-type calcium channels and mGluRs are critical for the induction of LTD in the 

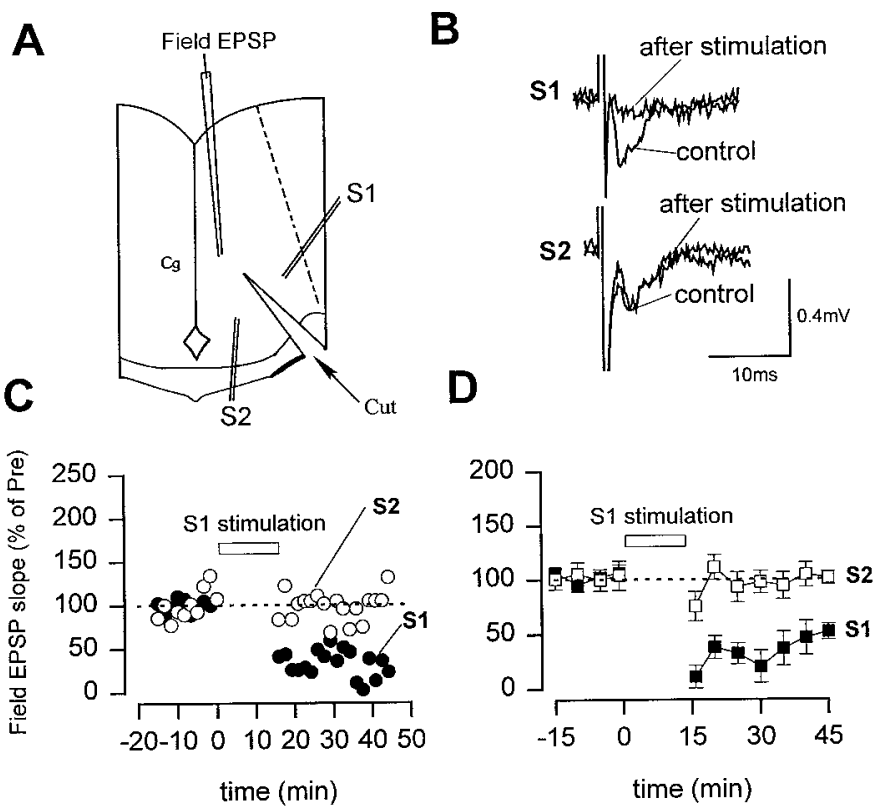

Figure 3. Two-pathway experiments showed that LTD is input-specific. $A$, Diagram of an ACC slice showing the placement of stimulating electrodes in two divided pathways $(S 1, S 2)$. $B$, Representative records of the EPSP recorded before and $30 \mathrm{~min}$ after $1 \mathrm{~Hz}$ stimulation in the stimulated pathway (S1) and control pathway (S2). C, D, Responses to paired-pulse stimulation (with a $50 \mathrm{msec}$ interval) were used to confirm the pathway-dependent induction of LTD $(n=6)$. Stimulation of S1 led to LTD only in the S1 pathway as shown by the synaptic response $(C) . D$, Summary results of two-pathway experiments $(n=6)$.

ACC. LTD was not affected in the presence of picrotoxin (100 $\mu \mathrm{M})$, a $\mathrm{GABA}_{\mathrm{A}}$ receptor antagonist, indicating that inhibitory influences are not required for LTD (Fig. 4D).

\section{Expression of immediate early genes after amputation}

Previous studies in the somatosensory cortex showed that a largescale functional reorganization occurs after peripheral amputation in both adult animals and humans (Wall, 1977; Merzenich et al., 1984; Pons et al., 1991; Ramachandran et al., 1992, 1995; Florence et al., 1998; Jones and Pons, 1998; Kaas, 1998; Merzenich, 1998). However, potential plastic changes within the ACC have not been studied. In contrast to somatosensory cortex neurons, which have topographical representation of the sensory receptive field of the body, ACC neurons often have a diff use receptive field and respond to stimuli applied to anywhere on the body surface (Vogt et al., 1979; Kenshalo et al., 1988; Devinsky et al., 1995; Sikes and Vogt, 1992). As a marker for synaptic activity in the ACC, the expression of two major IEGs, $c$-fos and NGFI-A, were examined at different time points after the amputation. $c$-fos and NGFI-A are transcription factors that are members of the leucine zipper and zinc finger families, respectively (Morgan and Curran, 1991; Munglani and Hunt, 1995). In animals receiving sham treatment, there was little expression of c-Fos and a basal level of NGFI-A (Fig. 5A, Table 1). However, we found that single-digit amputation in rats induced significant bilateral increases in the numbers of ACC cells expressing c-Fos or NGFI-A from $15 \mathrm{~min}$ to $2 \mathrm{~d}$, with maximum expression at 45 min (Fig. 5A, Table 1). $c$-fos has $\mathrm{Ca}^{2+} / \mathrm{CRE}$-like sequences in its promoter regions, and its transcription is regulated by pCREB (Ginty et al., 1993). Significant increases in the expression of pCREB were also found bilaterally in ACC after amputation compared with a basal level in sham-operated rats (Fig. 5B, Table 1). Unlike c-Fos and NGFI-A, the level of pCREB 2 weeks later was lower than that in normal rats.

\section{Loss of LTD after amputation}

LTD is modified during development, learning, and stress in the neocortex and hippocampus (Abraham and Bear, 1996; Hensch and Stryker, 1996; Kirkwood et al., 1996; Xu et al., 1997; Feldman et al., 1998; Rittenhouse et al., 1999). We next tested whether LTD in the ACC may be affected in rats receiving a third-digit amputation. In vitro experiments were performed in slices obtained from adult rats 45 min after amputation, a time when significant increases in the expression of the three IEGs were found (Table 1). LTD was almost completely abolished in slices taken at $45 \mathrm{~min}$ after amputation (Fig. 6B). The changes were bilateral; slices obtained from the cingulate cortex ipsilateral or contralateral to the amputated hindpaw digit showed a similar loss of LTD (ipsilateral, $n=3$; contralateral, $n=5$ ). Similar results were obtained with stimulation at another frequency $(5 \mathrm{~Hz}$ for $3 \mathrm{~min}$ ) ( $n=5$; data not shown). The loss of LTD persisted for many days after amputation. In slices taken $2 \mathrm{~d}(n=5 ; 115.1 \pm$ $10.7 \%$ of control 30 min after the stimulation) or 2 weeks (Fig. $6 C$ ) after amputation, LTD in the ACC was abolished.

To test whether the loss of LTD after amputation may be restricted to the ACC, we performed the same experiment in the PC from normal and amputated animals. Low-frequency stimulation $(1 \mathrm{~Hz}, 15 \mathrm{~min})$ produced long-lasting depression of synaptic responses in slices from both groups of rats (Fig. 7).

\section{DISCUSSION}

Peripheral deafferentation or amputation could cause massive plastic changes within cortical and subcortical structures (Kaas et al., 1999). For early changes, it is likely that plastic changes may occur between existent neuronal synapses, and for late changes, structural changes within the CNS, including formation of new synapses, could occur. In the present study, we found that amputation of a single digit of one hindpaw caused rapid and prolonged plastic changes in sensory synaptic responses. Altered synaptic plasticity in the ACC, a region critical for processing pain information in the CNS, may serve as an important synaptic mechanism for enhanced nociceptive transmission after deafferentation or amputation.

\section{LTD caused by repetitive stimulation in adult cingulate cortex}

Two forms of LTD have been reported in the CNS, distinguished by their sensitivity to the blockade of NMDA receptor antagonists: NMDA receptor-dependent LTD and NMDA receptorindependent LTD (see Boshakov and Siegelbaum, 1994; Deisseroth et al., 1996; Oliet et al., 1997). Physiological roles of NMDA receptor-dependent LTD have been indicated in several areas, such as in the visual cortex and hippocampus (Bear and Malenka, 1994). In this study, we have found that NMDA receptor-independent LTD is the major form of synaptic depression in slices from the ACC of adult rats. Unlike the posterior cingulate cortex, LTD in the ACC did not require activation of NMDA receptors (Hedberg and Stanton, 1996). In contrast, activation of L-type calcium channels and mGluRs is required for the induction of LTD.

More importantly, we demonstrate that slices of adult rats, after a third hindpaw digit amputation, fail to undergo synaptic depression induced by repetitive, low-frequency stimulation. Several mechanisms may contribute to the loss of LTD after ampu- 


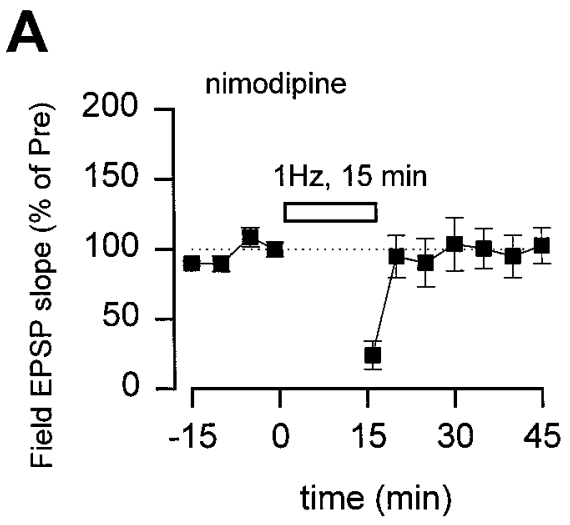

Figure 4. Blockade of LTD by nimodipine or MCPG. $A, B$, LTD was abolished in the presence of voltagegated L-type calcium channel blocker nimodipine (10 $\mu \mathrm{M} ; A$, squares; $n=5 ; 96.3 \pm 13.5 \%$ of control) but not NMDA receptor antagonist AP-5 $(100 \mu \mathrm{M}$; B, squares; $n=5,34.9 \pm 15.7 \%$ of control). Slices were pretreated with a drug for at least $30 \mathrm{~min}$ before low-frequency stimulation. $C, \mathrm{LTD}$ was also blocked in the presence of an mGluR antagonist MCPG $(500 \mu \mathrm{M} ; n=4 ; 94.1 \pm$ $20.3 \% ; p<0.01)$. $D$, Summary results for treatment with nimodipine, AP-5, MCPG, or $\mathrm{GABA}_{\mathrm{A}}$ receptor antagonist picrotoxin $(100 \mu \mathrm{M} ; n=3 ; 46.1 \pm 20.4 \%)$. ${ }^{*} p<$ 0.01 compared with the control group.
B

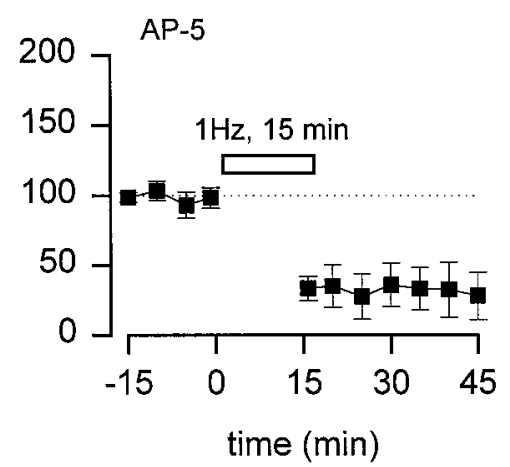

D

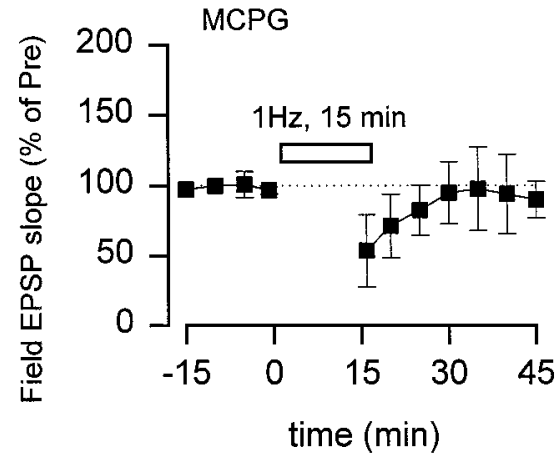

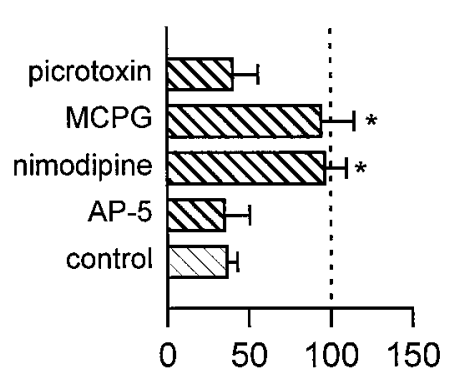

Field EPSP slope (\% of Pre) tation. First, occlusion of synaptic transmission could be induced by cortical depression after amputation. However, this seems unlikely to be the case. Basal synaptic responses to presynaptic transmission do not seem to be significantly different from that of control animals. More importantly, we found that synaptic responses to peripheral electrical stimulation were enhanced after amputation (our unpublished observations), although the exact central loci for these changes have not been determined. Second, amputation could cause plastic changes in the postsynaptic cells and thus affect the induction of LTD. We have shown that amputation leads to a large-scale activation of neurons in the ACC and potentiation of synaptic transmission. Therefore, it is likely that enhanced postsynaptic excitability contributes to the failure to induce LTD after amputation. Previous studies in both hippocampus and visual cortex showed that postsynaptic membrane depolarization could determine whether synaptic transmission undergoes potentiation or depression (Stanton and Sejnowski, 1989; Artola et al., 1990; Stevens, 1990). Our results using different kinds of IEG staining also found that many cells in the ACC showed plastic changes of synaptic activity after amputation. We favor the second possibility that postsynaptic changes affect the induction of LTD. However, we cannot exclude possible unknown presynaptic mechanisms, which could also contribute to the loss of LTD by amputation.

\section{Plasticity in the ACC after amputation}

In primitive sensory neurons of invertebrates, both conditionrelated learning and injury of peripheral axons are reported to cause an increase in excitability (Walters et al., 1991; Woolf and Waters, 1991). In mammalians, similar changes have been studied in the dorsal horn of the spinal cord (Woolf, 1992). Prolonged activation of nociceptive afferent fibers or tissue and nerve injury induced a long-term increase in sensory transmission in dorsal horn neurons, including ascending projection neurons. The involvement of supraspinal structures has been less investigated, although there is cumulative evidence suggesting that many supraspinal structures, including those that send descending projection pathways, play an important role after tissue or nerve injury (e.g., amputation). The present study shows that synaptic plasticity of excitatory glutamatergic transmission in the ACC was altered after amputation of a single digit of the hindpaw. This, together with numerous reports using divergent approaches (Katz and Melzack, 1990; Merzenich and Sameshima, 1993), suggests that memory mechanisms in both invertebrates and vertebrates may have evolved from animals' adaptive responses to injury. Changes in glutamatergic synaptic responses have been implicated in development, learning, and memory storage (Tsumoto, 1992; Bliss and Collingridge, 1993; Bear and Malenka, 1994; Linden, 1994; Lisman, 1994; Larkman and Jack, 1995; Nicoll and Malenka, 1995; Singer, 1995; Bear and Abraham, 1996). Our results support previous evidence of cortical reorganization in the somatosensory cortex during learning or after amputation (Wall, 1977; Merzenich et al., 1984; Pons et al., 1991; Ramachandran et al., 1992, 1995; Florence et al., 1998; Jones and Pons, 1998; Kaas, 1998; Merzenich, 1998).

\section{Functional implications}

Studies from animals and humans consistently suggest that the ACC plays an important role in nociception and pain, in addition to its important roles in other physiological functions (Devinsky et al., 1995). Lesion of the rat medial frontal cortex, including the ACC, significantly increased hot-plate latency (Pastoriza et al., 1996). In patients with frontal lobotomies or cingulotomies, the unpleasantness of pain is abolished (Foltz and White, 1962; Hurt 


\section{A \\ c-Fos \\ NGFI-A}
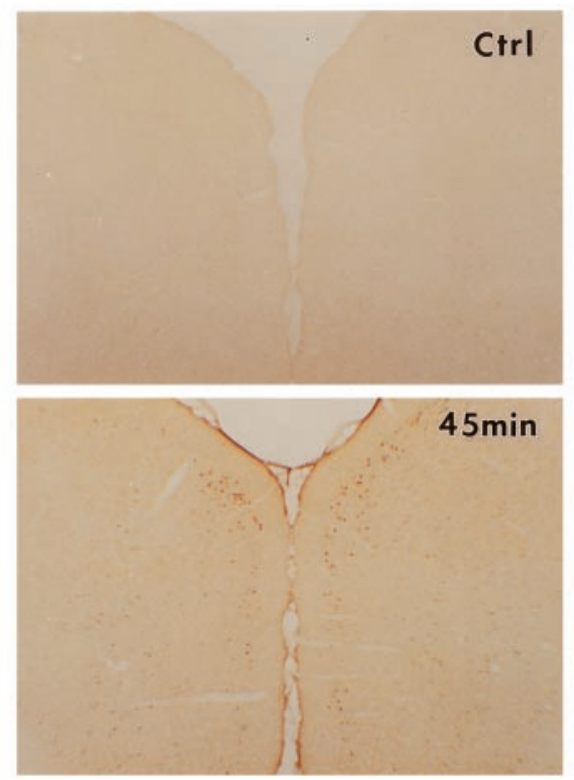

\section{pCREB}
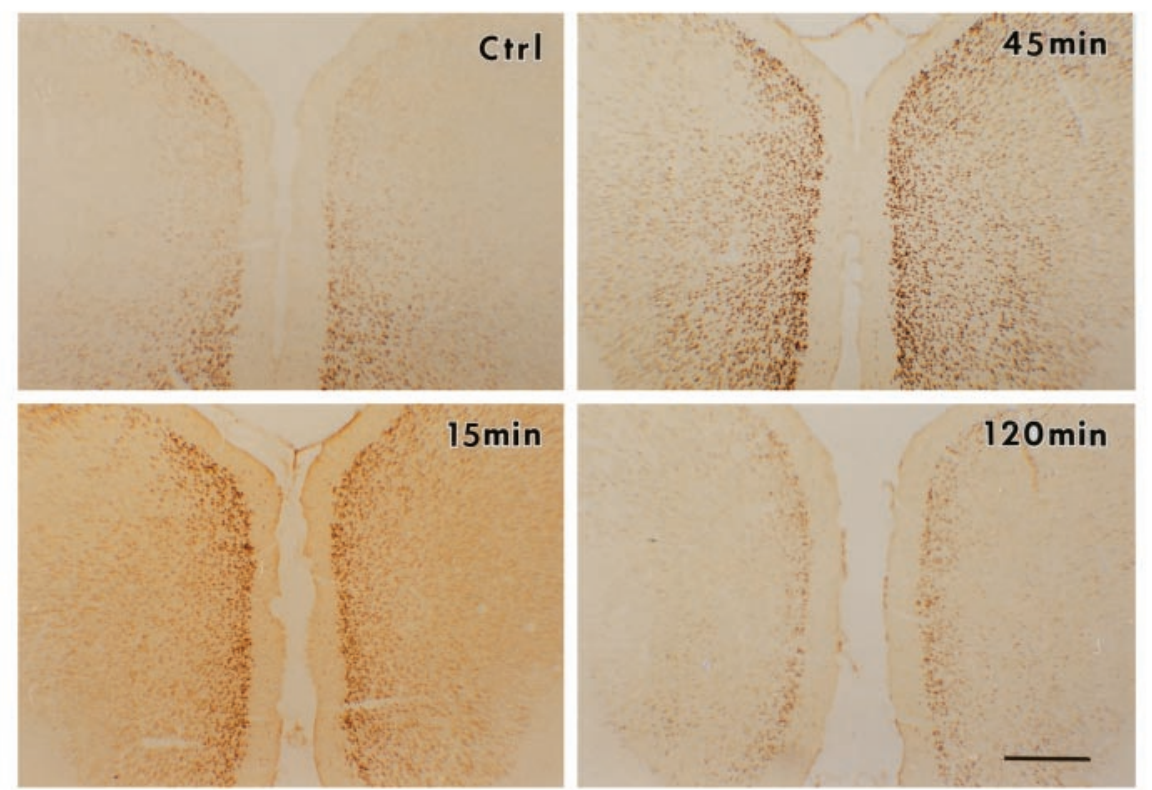
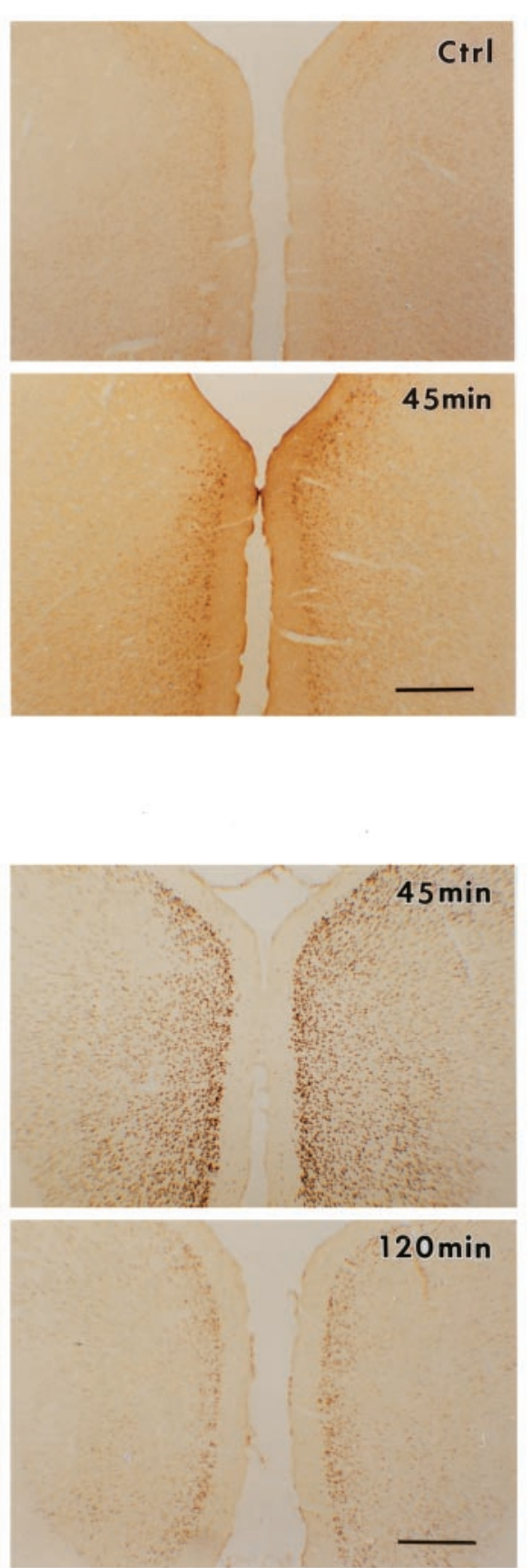

Figure 5. Potentiation of IEG expression in the ACC after the amputation. Photomicrographs showing expression of c-Fos and NGFI-A $(A)$ and phosphorylation of CREB $(B)$ in the coronal ACC sections from sham animals (Ctrl) and animals at different times after the amputation of the unilateral hindpaw third digit. Scale bars, 500 $\mu \mathrm{m}$. The numbers of c-Fos-, NGFI-A-, and pCREB-immunoreactive cells increased bilaterally after the amputation (see Table 1 for summary).

Table 1. Expression of c-Fos, pCREB, and NGFI-A in the rat ACC after unilateral amputation of a single digit of the hindpaw

\begin{tabular}{|c|c|c|c|c|c|}
\hline & & \multirow{2}{*}{$\begin{array}{l}\text { Baseline } \\
(n=10 \text { rats })\end{array}$} & \multicolumn{3}{|l|}{ Amputation } \\
\hline & & & $45 \min (n=6)$ & $2 \mathrm{~d}(n=4)$ & 2 weeks $(n=4)$ \\
\hline \multirow[t]{2}{*}{ c-Fos } & Contralateral & $18 \pm 5$ & $217 \pm 48^{*}$ & $115 \pm 22^{*}$ & $38 \pm 15$ \\
\hline & Ipsilateral & $19 \pm 4$ & $173 \pm 52^{*}$ & $63 \pm 18^{*}$ & $18 \pm 4$ \\
\hline \multirow[t]{2}{*}{ pCREB } & Contralateral & $530 \pm 63$ & $1011 \pm 112^{*}$ & $769 \pm 60^{*}$ & $39 \pm 20^{*}$ \\
\hline & Ipsilateral & $516 \pm 57$ & $910 \pm 143^{*}$ & $706 \pm 81^{*}$ & $29 \pm 14^{*}$ \\
\hline \multirow{2}{*}{ NGFI-A } & Contralateral & $250 \pm 27$ & $494 \pm 86^{*}$ & $585 \pm 57^{*}$ & $282 \pm 64$ \\
\hline & Ipsilateral & $255 \pm 38$ & $367 \pm 57^{*}$ & $545 \pm 54^{*}$ & $269 \pm 49$ \\
\hline
\end{tabular}

Data are expressed as mean \pm SE. ${ }^{*} p<0.05$ compared with the expression level in sham animals. 


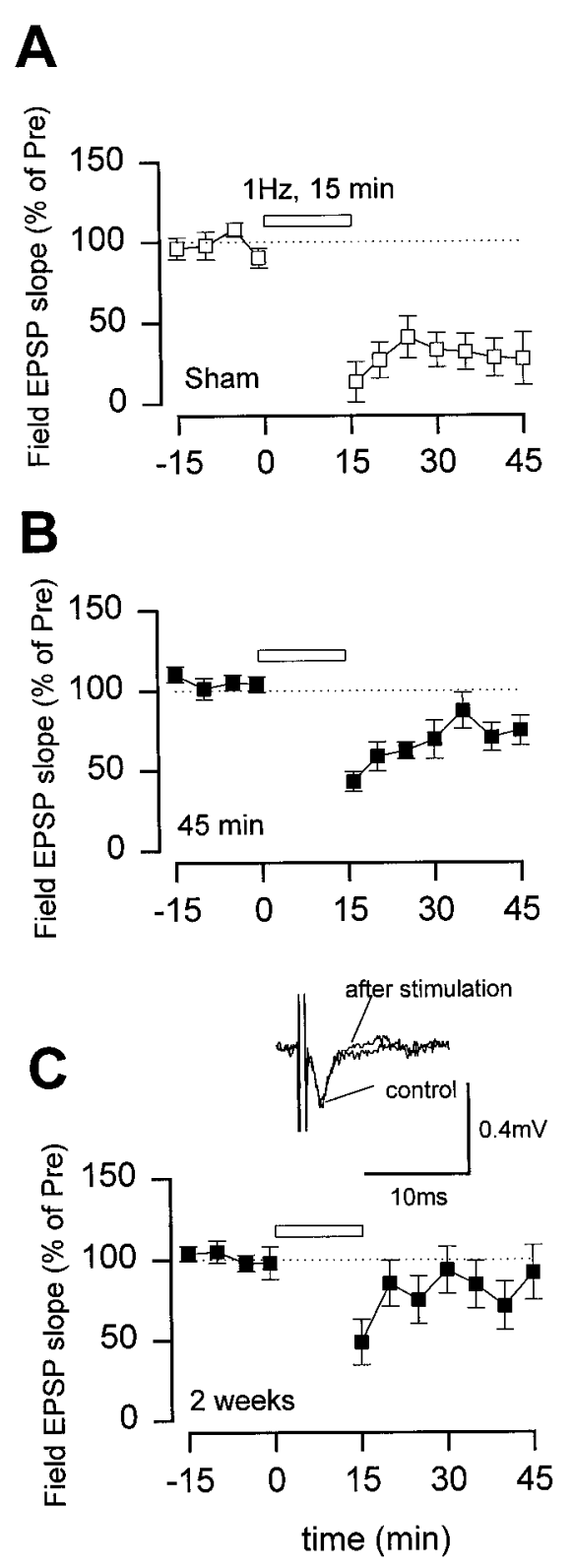

Figure 6. Long-lasting loss of LTD in the ACC after the amputation. LTD recorded from ACC slices in sham animals $(A)(n=5 ; 28.4 \pm$ $14.0 \%)$ and rats at $45 \min (B)(n=7 ; 76.5 \pm 7.8 \% ; p<0.05$ compared with the control group) and 2 weeks $(C)(n=5 ; 91.1 \pm 18.3 \% ; p<0.05$ compared with the control group) after the amputation. Inset in $C$, Representative records of the EPSP recorded before and 30 min after 1 $\mathrm{Hz}$ stimulation.

and Ballantine, 1973; Yarnitsky et al., 1988; Stanton and Sejnowski, 1989; Artola et al., 1990; Stevens, 1990; Davis et al., 1994; Talbot et al., 1995; Craig et al., 1996). Electrophysiological recordings from both animals and humans demonstrate that neurons within the ACC respond to noxious stimuli, including nociceptive specific neurons (animals: Devinsky et al., 1995; Kenshalo et al., 1988; Sikes and Vogt, 1992; Vogt et al., 1979; humans: Hutchison et al., 1999). Neuroimaging studies further confirm these observations and show that the ACC, together with other cortical structures, are activated by acute noxious stimuli (Talbot et al., 1991; Vogt et al., 1996; Davis et al., 1997; Derbyshire et al., 1998; Lenz et al., 1998; Paulson et al., 1998; Hutchison et al.,
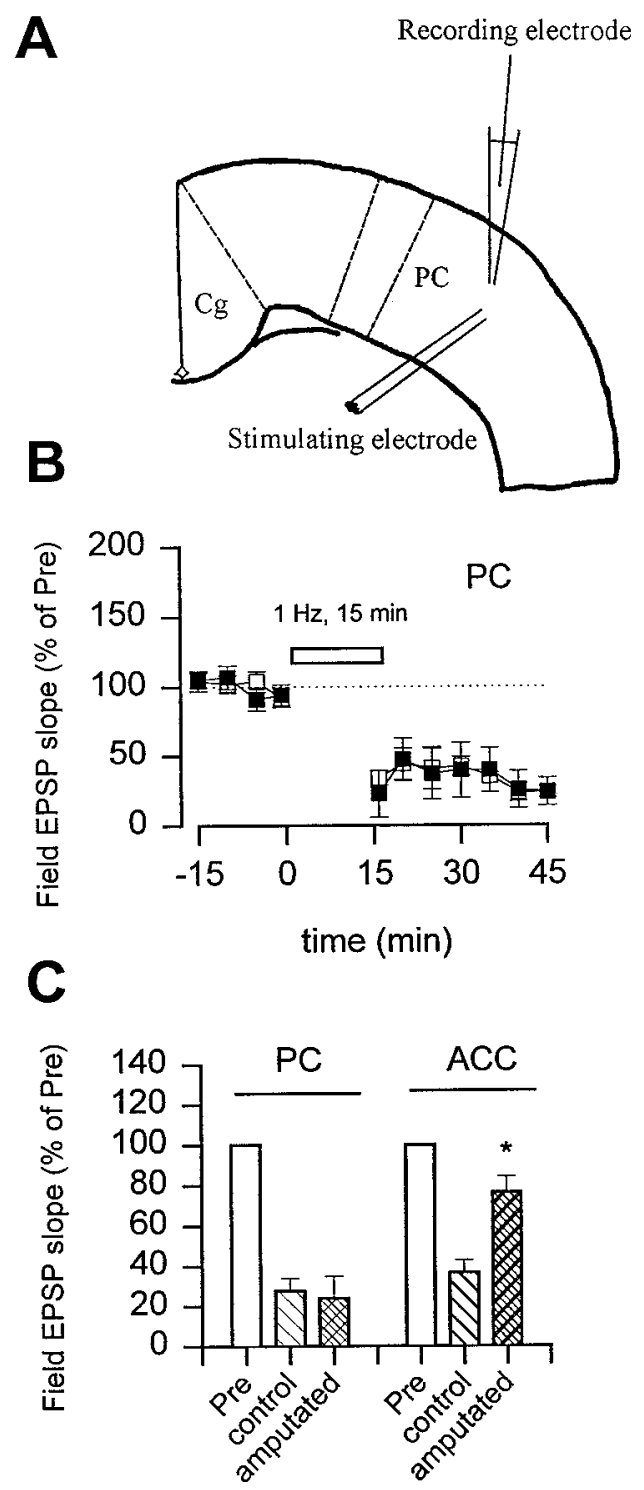

Figure 7. Selective loss of LTD in the ACC but not the PC after the amputation. $A$, Diagram of a cortical slice showing the placement of recording and stimulating electrodes in the PC. $B$, Repetitive stimulation ( $1 \mathrm{~Hz}, 15 \mathrm{~min}$; open bar) induced a long-lasting depression of synaptic response in sham animals (open squares; $n=3 ; 27.6 \pm 6.3 \%$ of control; $p<0.01)$. At 45 min after amputation of the third hindpaw digit, similar LTD was induced in slices of PC ( filled squares; $n=4 ; 24.0 \pm 11.0 \%$ ). $C$, The amputation produced a selective loss of LTD in the ACC but not the $\mathrm{PC}$ areas in the same cortical slices.

1999). Our present studies using IEG-encoded protein immunostaining techniques and neuronal plasticity showed that neurons within the ACC could show plastic changes to amputation. In the same animals, behavioral hyperalgesia to noxious stimuli was also observed (our unpublished observations). Although it is unlikely that changes in synaptic plasticity within the ACC alone explain behavioral hyperalgesia, long-lasting changes within the ACC could certainly contribute to various pain-related functional alterations after amputation. In the present study, we did not address potential changes in other cortical and subcortical areas, such as the somatosensory cortex, thalamus, and spinal cord. It is possible that similar plastic changes may occur in these areas as well. Understanding plastic changes within the areas involved in 
pain transmission and modulation after amputation could allow us to treat phantom pain in human amputees. From a clinical perspective, our studies provide a cellular model for studying synaptic mechanisms for phantom pain. These synaptic changes provide a probe to evaluate the effect of different drugs that could be potentially useful for preoperative and postoperative treatment (Jacobson and Chabal, 1989; Katz and Melzack, 1990; Richmond et al., 1993; Woolf and Chong, 1993).

\section{REFERENCES}

Abraham WC, Bear MW (1996) Metaplasticity: the plasticity of synaptic plasticity. Trends Neurosci 19:126-130.

Artola A, Brocher S, Singer W (1990) Different voltage-dependent thresholds for inducing long-term depression and long-term potentiation in slices of rat visual cortex. Nature 347:69-72.

Bashir ZI, Janes DE, Sunter DC, Watkins JC, Collingridge GL (1993) Metabotropic glutamate receptors contribute to the induction of longterm depression in the CA1 region of the hippocampus. Eur J Pharmacol 239:265-266.

Bear MF, Abraham WC (1996) Long-term depression in hippocampus. Annu Rev Neurosci 19:437-462.

Bear MF, Malenka RC (1994) Synaptic plasticity: LTP and LTD. Curr Opin Neurobiol 4:389-399.

Birbaumer N, Lutzenberger W, Montoya P, Larbig W, Unertl K, Topfner S, Grodd W, Taub E, Flor H (1997) Effects of regional anesthesia on phantom limb pain are mirrored in changes in cortical reorganization. J Neurosci 17:5503-5508.

Bliss TV, Collingridge GL (1993) A synaptic model of memory: longterm potentiation in the hippocampus. Nature 361:31-39.

Boshakov VY, Siegelbaum SA (1994) Postsynaptic induction and presynaptic expression of hippocampal long-term depression. Science 264:1148-1152.

Buonomano DV, Merzenich MM (1998) Cortical plasticity: from synapses to maps. Annu Rev Neurosci 21: 149-186.

Craig AD, Reiman EM, Evans A, Bushnell MC (1996) Functional imaging of an illusion of pain. Nature 384:258-260.

Cummings JA, Mulkey RM, Nicoll RA, Malenka RC (1996) $\mathrm{Ca}^{2+}$ signaling requirements for long-term depression in the hippocampus. Neuron 16:825-833.

Davis KD, Hutchison WD, Lozano AM, Dostrovsky JO (1994) Altered pain and temperature perception following cingulotomy and capsulotomy in a patient with schizoaffective disorder. Pain 59:189-199.

Davis KD, Taylor SJ, Crawley AP, Wood ML, Mikulis RJ (1997) Functional MRI of pain- and attention-related activations in the human cingulate cortex. J Neurophysiol 77:3370-3380.

Deisseroth K, Bito H, Tsien RW (1996) Signaling from synapse to nucleus: postsynaptic CREB phosphorylation during multiple forms of hippocampal synaptic plasticity. Neuron 16:89-101.

Derbyshire SW, Vogt BA, Jones AK (1998) Pain and Stroop interference tasks activate separate processing modules in anterior cingulate cortex. Exp Brain Res 118:52-60.

Devinsky O, Morrell MJ, Vogt BA (1995) Contributions of anterior cingulate cortex to behavior. Brain 118:279-306.

Dudek SM, Bear MF (1992) Homosynaptic long-term depression in area CA1 of hippocampus and effects of $N$-methyl-D-aspartate receptor blockade. Proc Natl Acad Sci USA 89:4363-4367.

Feldman DE, Nicoll RA, Malenka RC, Issac JTR (1998) Long-term depression at thalamocortical synapses in developing rat somatosensory cortex. Neuron 21:347-357.

Flor H, Elbert T, Knetcht S, Wienbruch C, Pantev C, Birbaumer N, Larbig W, Taub E (1995) Phantom-limb pain as a perceptual correlate of cortical reorganization following arm amputation. Nature 375:482-484.

Florence SL, Taub HB, Kaas JH (1998) Large-scale sprouting of cortical connections after peripheral injury in adult macaque monkeys. Science 282:1117-1121.

Foltz EL, White LE (1962) Pain "relief" by frontal cingulotomy. J Neurosurg 19:89-100.

Gilbert CD (1996) Plasticity in visual perception and physiology. Curr Opin Neurobiol 6:269-274.

Gilbert CD, Wiesel TN (1992) Receptive field dynamics in adult primary visual cortex. Nature 356:150-152.

Ginty DD, Kornhauser JM, Thompson MA, Bading H, Mayo KE, Ta- kahashi JS, Greenberg ME (1993) Regulation of CREB phosphorylation in the suprachiasmatic nucleus by light and a circadian clock. Science 260:238-241.

Hedberg TG, Stanton PK (1996) Long-term plasticity in cingulate cortex requires both NMDA and metabotropic glutamate receptor activation. Eur J Pharmacol 310:19-27.

Hensch TK, Stryker HP (1996) Ocular dominance plasticity under metabotropic glutamate receptor blockade. Science 272:554-557.

Hurt RW, Ballantine Jr HT (1973) Stereotactic anterior cingulate lesions for persistent pain: a report on 68 cases. Clin Neurosurg 21:334-351.

Hutchison WD, Davis KD, Lozano AM, Tasker RR, Dostrovsky JO (1999) Pain-related neurons in the human cingulate cortex. Nat Neurosci 2:403-405.

Jacobson L, Chabal C (1989) Prolonged relief of acute postamputation phantom limb pain with intrathecal fentanyl and epidural morphine. Anesthesiology 71:984-985.

Jensen TS, Rasmussen P (1994) Phantom pain and other phenomena after amputation. In: Textbook of pain (Wall PD, Melzack R, eds), pp 651-666. New York: Churchill Livingstone.

Jones EG, Pons TP (1998) Thalamic and brainstem contributions to large-scale plasticity of primate somatosensory cortex. Science 282:1121-1125.

Kaas JH (1991) Plasticity of sensory and motor maps in adult mammals. Annu Rev Neurosci 14:137-167.

Kaas JH (1998) Phantoms of the brain. Nature 391:331-333.

Kaas JH, Florence SL, Jain N (1999) Subcortical contributions to massive cortical reorganizations. Neuron 22:657-660.

Kato N (1993) Dependence of long-term depression on postsynaptic metabotropic glutamate receptors in visual cortex. Proc Natl Acad Sci USA 90:3650-3654.

Katz J, Melzack R (1990) Pain "memories" in phantom limbs: review and clinical observations. Pain 43:319-336.

Kenshalo Jr DR, Chudler EH, Anton F, Dubner R (1988) SI nociceptive neurons participate in the encoding process by which monkeys perceive the intensity of noxious thermal stimulation. Brain Res 454:378-382.

Kilgard MP, Merzenich MM (1998) Cortical map reorganization enabled by nucleus basalis activity. Science 279:1714-1718.

Kirkwood A, Dudek SM, Gold JT, Aizenman CD, Bear MF (1993) Common forms of synaptic plasticity in the hippocampus and neocortex in vitro. Science 260:1518-1521.

Kirkwood A, Rioult MG, Bear MF (1996) Experience-dependent modification of synaptic plasticity in visual cortex. Nature 381:526-528.

Koyama T, Tanaka YZ, Mikami A (1998) Nociceptive neurons in the macaque anterior cingulate activate during anticipation of pain. NeuroReport 9:2663-2667.

Larkman AU, Jack JJB (1995) Synaptic plasticity: hippocampal LTP. Curr Opin Neurobiol 5:324-334.

Lenz FA, Rios M, Zirh A, Chau D, Krauss G, Lesser RP (1998) Painful stimuli evoke potentials recorded over the human anterior cingulate gyrus. J Neurophysiol 79:2231-2234.

Linden DJ (1994) Long-term synaptic depression in the mammalian brain. Neuron 12:457-472.

Lisman J (1994) The CaM kinase II hypothesis for the storage of synaptic memory. Trends Neurosci 17:406-412.

Lorenz J, Kohlhoff H, Hansen HC, Kunze K, Bromm B (1998) Abetafiber mediated activation of cingulate cortex as correlate of central post-stroke pain. NeuroReport 9:659-663.

Melzack R (1990) Phantom limbs and the concept of a neuromatrix. Trends Neurosci 13:88-92.

Merzenich M (1998) Long-term change of mind. Science 282:1062-1063.

Merzenich MM, Sameshima K (1993) Cortical plasticity and memory. Curr Opin Neurobiol 3:187-196.

Merzenich MM, Nelson RJ, Stryker MP, Cynader MS, Schoppmann A, Zook JM (1984) Somatosensory cortical map changes following digit amputation in adult monkeys. J Comp Neurol 224:591-605.

Morgan JL, Curran T (1991) Stimulus-transcription coupling in the nervous system: involvement of the inducible proto-oncogenes fos and jun. Annu Rev Neurosci 14:421-451.

Mulkey RM, Malenka RC (1992) Mechanisms underlying induction of homosynaptic long-term depression in area CA1 of the hippocampus. Neuron 9:967-975.

Munglani R, Hunt SP (1995) Proto-oncogenes: basic concepts and stimulation induced changes in the spinal cord. Prog Brain Res 104:283-298. 
Nicoll RA, Malenka RC (1995) Contrasting properties of two forms of long-term potentiation in the hippocampus. Nature 377:115-118.

Oliet SH, Malenka RC, Nicoll RA (1997) Two distinct forms of longterm depression coexist in CA1 hippocampal pyramidal cells. Neuron 18:969-982.

Pastoriza LN, Morrow TJ, Casey KL (1996) Medial frontal cortex lesions selectively attenuate the hot plate response: possible nocifensive apraxia in the rat. Pain 64:11-17.

Paulson PE, Minoshima S, Morrow TJ, KL Casey (1998) Gender differences in pain perception and patterns of cerebral activation during noxious heat stimulation in humans. Pain 76:223-229.

Paxinos G, Watson C (1997) The rat brain in stereotaxic coordinates. San Diego: Academic.

Pons TP, Garraghty PE, Ommaya AK, Kaas JH, Taub E, Mishin M (1991) Massive cortical reorganization after sensory deafferentation in adult macaques. Science 252:1857-1860.

Rainville P, Duncan GH, Price DD, Carrier B, Bushnell MC (1997) Pain affect encoded in human anterior cingulate but not somatosensory cortex. Science 277:968-971.

Ramachandran VS (1993) Behavioral and magnetoencephalographic correlates of plasticity in the adult human brain. Proc Natl Acad Sci USA 90:10413-10420.

Ramachandran VS, Rogers-Ramachandran DC, Stewart M (1992) Perceptual correlates of massive cortical reorganization. Science 258:1159-1160.

Ramachandran VS, Rogers-Ramachandran DC, Cobb S (1995) Touching the phantom limb. Nature 377:489-490.

Richmond CE, Bromley LM, Woolf CJ (1993) Preoperative morphine pre-empts postoperative pain. Lancet 342:73-75.

Rittenhouse CD, Shouval HZ, Paradisco MA, Bear MF (1999) Monocular deprivation induces homosynaptic long-term depression in visual cortex. Nature 397:347-350.

Sah P, Nicoll RA (1991) Mechanisms underlying potentiation of synaptic transmission in rat anterior cingulate cortex in vitro. J Physiol (Lond) 433:615-630.

Sherman RA, Sherman CJ, Gall NG (1980) A survey of current phantom limb pain treatment in the United States. Pain 8:85-99.

Sikes RW, Vogt BA (1992) Nociceptive neurons in area 24 of rabbit cingulate cortex. J Neurophysiol 68:1720-1732.

Singer W (1995) Development and plasticity of cortical processing architectures. Science 270:758-764.

Stanton PK, Sejnowski TJ (1989) Associative long-term depression in the hippocampus induced by hebbian covariance. Nature 339:215-218.

Stevens CF (1990) Neurobiology. A depression long awaited. Nature 347:16.

Talbot JD, Marrett S, Evans AC, Meyer E, Bushnell MC, Duncan GH (1991) Multiple representations of pain in human cerebral cortex. Science 251:1355-1358.
Talbot JD, Vilemure JG, Bushnell MC, Duncan GH (1995) Evaluation of pain perception after anterior capsulotomy: a case report. Somatosens Mot Res 12:115-126.

Tanaka E, North RA (1994) Opioid actions on rat anterior cingulate cortex neurons in vitro. J Neurosci 14:1106-1113.

Tolle TR, Kaufmann T, Siessmeier T, Lautenbacher S, Berthele A, Munz F, Ziglgansberger W, Willoch F, Schwaiger M, Conrad B, Bertenstain $P$ (1999) Region-specific encoding of sensory and affective components of pain in the human brain: a positron emission tomography correlation analysis. Ann Neurol 45:40-47.

Traub RJ, Silva E, Gebhart GF, Solodkin A (1996) Noxious colorectal distention induced-c-Fos protein in limbic brain structures in the rat. Neurosci Lett 215:165-168.

Tsumoto T (1992) Long-term potentiation and long-term depression in the neocortex. Prog Neurobiol 39:209-228.

Vogt BA, Rosene DL, Pandya DN (1979) Thalamic and cortical afferents differentiate anterior from posterior cingulate cortex in the monkey. Science 204:205-207.

Vogt BA, Derbyshire S, Jones AK (1996) Pain processing in four regions of human cingulate cortex localized with co-registered PET and MR imaging. Eur J Neurosci 8:1461-1473.

Wall JT (1988) Variable organization in cortical maps of the skin as an indication of the lifelong adaptive capacities of circuits in the mammalian brain. Trends Neurosci 11:549-557.

Wall PD (1977) The presence of ineffective synapses and the circumstances which unmask them. Philos Trans R Soc Lond B Biol Sci 278:361-372.

Walters ET, Alizadeh H, Castro GA (1991) Similar neuronal alterations induced by axonal injury and learning in Aplysia. Science 253:797-799.

Weinberger NM (1995) Dynamic regulation of receptive fields and maps in the adult sensory cortex. Annu Rev Neurosci 18:129-158.

Woolf CJ (1992) Excitability changes in central neurons following peripheral damage: role of central sensitization in the pathogenesis of pain. In: Hyperalgesia and allodynia (Willis Jr WD, ed), pp 221-243. New York: Raven.

Woolf CJ, Chong MS (1993) Preemptive analgesia-treating postoperative pain by preventing the establishment of central sensitization. Anesth Analg 77:362-379.

Woolf CJ, Waters ET (1991) Common patterns of plasticity contributing to nociceptive sensitization in mammals and Aplysia. Trends Neurosci 14:74-78.

Xu L, Anwyl R, Rowan MJ (1997) Behavioral stress facilitates the induction of long-term depression in the hippocampus. Nature 387:497-500

Yarnitsky D, Barron SA, Bental E (1988) Disappearance of phantom pain after focal brain infarction. Pain 32:285-287. 